\title{
Investigation on the Crack and Thinning Behavior of Aluminum Alloy 5052 Sheet in Stretch Flanging Process
}

\author{
Surendra Kumar $\cdot$ M. Ahmed $\cdot$ S. K. Panthi
}

Submitted: 5 October 2019/in revised form: 28 February 2020/Published online: 28 July 2020

(C) ASM International 2020

\begin{abstract}
Stretch flanging is the important sheet metalforming process which is widely used in automobile and aerospace sectors. The formability of sheet metal depends on various parameters such as material properties, geometry of the tool setup and process parameters. In the present work, effects of different die radius and sheet width on deformation behavior of sheet are studied by FEM simulation and experiments. The predicted FEM results are presented in the form of edge crack location and its propagation, crack length, forming load and strain distribution in sheet along the die profile radius. This study indicates that crack length increases with increase in the sheet width, while the crack length decreases with increase in the die radius. It is found that the crack propagation in stretch flanging process is affected by the strain distribution in sheet and this distribution of strain depends on many parameters. The crack initiates during deformation of the sheet at the die corner edge and propagates toward the center of the sheet along the die profile radius. Simulation results are compared with the experimental one in terms of crack length and variation in sheet thickness. FE simulation results are found in very good agreement with experimental results. Fractography study is also presented in terms of size, shape of the dimples along with their distribution on the fractured surface.
\end{abstract}

\footnotetext{
S. Kumar

Academy of Scientific and Innovative Research (AcSIR), Bhopal 462026, India

S. Kumar · M. Ahmed · S. K. Panthi $(\bowtie)$

Council of Scientific and Industrial Research (CSIR)-Advanced

Materials and Processes Research Institute (AMPRI), Bhopal 462026, India

e-mail: sanjay_panthi@yahoo.co.in
}

Keywords Stretch flanging process .

Finite element simulation - Edge crack · Crack length .

Forming load - Strain and thickness distribution .

Fractography

\section{Introduction}

Flanging is one type of bending process which is used in automotive, aerospace and household appliance industries to manufacture the various components. In the stretch flanging process, a definite part of the sheet is fixed between the die and the blank-holder and the free part of sheet is bend to $90^{\circ}$ to form the concave shaped flange. In this process, sheet material is stretched circumferentially along a bend line [1,2]. The flanged portion is generally used to provide the stiffness to a component, smoothens the sharp edges of the part and to assemble the different parts $[3,4]$. In this process, optimization of tensile or hoop stress is a major challenge that is responsible for the satisfactorily deformation of the sheet during flange formation. If this tensile stress exceeds beyond a certain limit, generation of cracks takes place in the sheet that is undesirable. Necking, localized thinning and localized fracture are the major defects in the sheet during flanging operation. These defects can be minimized with the help of FEM simulation by designing the process in advance. FEM simulation is a valuable tool for the prediction of deformation behavior of sheet and load requirements in flanging process within efficient time. It has also less equipment cost as compared to experimental one, which is a cumbersome process to optimize any process [5].

In the past, various researchers have been attempted to predict the failure phenomenon in the sheet metal-forming 
operation by using FEM simulation. Wang and Wenner [6] used numerical procedure for the study of strain and stress distribution in stretch flanging process. This theory is based on the total membrane strain of rigid-plasticity and approximate theory. $\mathrm{Li}$ et al. [7] analyzed the stretch flanging of $\mathrm{V}$-shaped sheet metal forming and study the effect of material parameters and geometrical parameters on flanging. An analytical model was developed for axisymmetric case on total strain theory and membrane assumption. $\mathrm{Hu}$ et al. [8] found that the smaller die radius than the punch radius is detrimental for the deformation. Further, this study also presented the effect of geometrical parameters and anisotropic characteristics on stretchcurved flanging by using different sheet metal-forming processes. Hu et al. [9] developed two analytical model for analysis of introflexion/stretch and outcurve/shrink flanges and used them to predict the trim-line of the blank and the shape of the rolling-stock and it is based on the total plasticity theory and the membrane strain assumption. Asnafi [10] studied the fracture limit in vertical stretch and shrink flanging by fluid-forming process and compared the results, experimental results with theoretical predictions. Yoshida et al. [11] prevented the crack initiation in highstrength steel sheets by using burring process and developed the suitable die shape and piercing method. The method of stretch flangeability was improved by using the side bending test method and limit diagram. Paul et al. [12] analyzed the forming limit diagrams (FLD) on the basis of strain and stress. Voswinckel et al. [13] used the method for improving the geometrical accuracy in flanging process by incremental sheet metal-forming method and new adaptive blank-holder technique. Lu et al. [14] developed two models, forward and inverse model by using adaptive network-based fuzzy inference system (ANFIS) for the prediction of initial circle hole diameter and deformed circle hole diameter in the sheet bore-expanding process. Zhang et al. [15] proposed the analytical model for the prediction of circumferential strain. This model is based on uniaxial stress in shrink flanging assumption. Chen et al. [16] studied the failure due to wrinkling in shrink flanging process by using the rubber forming process. It is based on the effect of four points such as-die radius, flange length, die fillet radius and forming pressure in aluminum alloy AA2024-O, AA7075-O and 2024-T3 sheet metal. Cao et al. [17] analyzed the onset of the wrinkling condition based on the energy method in shrink flanging process. Kasaei et al. [18] developed the mathematical model and studied the flange wrinkling on the basis of FEM simulation in flexible roll forming process. Wang et al. [19] proposed the analytical approach (model) for the prediction of wrinkling in sheet metal flange-forming operation under a constant binding force and pressure. Centeno et al. [20] studied the formability of aluminum alloy AA 2024-T3 sheet in different sheet metal-forming processes such as stretching, stretch bending and single-point incremental forming. Dewang et al. [21] studied the effect of punch-die clearance, coefficient of friction, punch and die profile radius on strain distribution for the prediction of crack location and propagation of aluminum alloy AA-5052 sheet metal blank. Feng et al. [22] studied the effect of geometrical parameters on the formability of stretch curved flanging by using large-step static implicit FE code and proposed that punch curvature radius should be larger than the die radius for the better results. Yohei Abe et al. [23] used the gradually contacting punch approach for improving the stretch flangeability of ultra-high strength steel (UHSS) sheet. Inclined bottom punch was used to reduce the tensile stress around the corner edge of the sheet. Sartkulvanich et al. [24] developed the FEM model for the characterization of blank edge quality for different punch/die clearance of advanced high-strength steel (AHSS) in stretch flanging process. Vafaeesefat Abbas and Khanahmadlu Morteza [25] compared the FEM simulation with experimental results in terms of shell-element in stretch $z$-flange-forming process. Golovashchenko [26] improved the quality of trimming process in stretch flanging of aluminum alloys AA6111-T4 sheet. Wen et al. [27] used tapered shoulder tool like a two-step procedure in flanging process of aluminum alloys AA 6061 and it is based on single-point incremental sheet-forming (ISF) technique. McDougall et al. [28] studied on the fracture in the deep drawing of steel sheet. It was revealed from metallographic evaluation that a severe variation with respect to grain size through the thickness of the steel sheet, as well as a slight segregation of pearlite. Gupta et al. [29] carried out a detailed microstructural analysis, mechanical properties evaluation on the samples drawn from the failed deep drawing component. Pantazopoulos and Sampani [30] carried out the Failure Analysis of Fractured Deep-Drawn Aluminum Circles and revealed that the tensile strength was leading to fracture during the process. Wu and Zou [31] studied on deep drawing of a coated metal sheet by finite element simulation and dimensional analysis. A failure map was established based on a few dimensionless process parameters, which can be divided into three regions, i.e., fracture, wrinkling and success. Yoganjaneyulu and Narayanan [32] carried out investigation to study and compare the forming limit diagrams (FLDs) and fracture limit curves (FLCs) of titanium grade 2 and titanium grade 4 sheets. Kumbhar [33] discussed on different failures like wrinkling, fracture, tearing and earring of the sheet metal in deep drawing process that are generally experienced in industries.

In the past few years, a lot of research had been done in the field of different sheet metal forming processes but less focus is given on the curved flanging process which is 
widely used in automobile industries, aerospace industries and in the manufacturing of household components. FE simulation tool like ABAQUS/Explicit software is capable in designing the tool setup and various process parameters before the experimental setup for such manufacturing process, which helps in reducing the manufacturing cost. Failure likes crack at the edge corner of the flange occurs in stretch flange-forming process depends on the strain distribution in sheet during deformation, and this distribution of strain depends on many geometrical and process parameters like die radius, flange length, friction, punch profile, width of sheet and sheet profile. In this study, effect of the sheet width and the die radius are investigated on the aluminum alloy AA-5052 sheet metal blank. Effect of others parameters are also studied and has been published in the other manuscript [34]. The work was carried out by ABAQUS/Explicit software to predict the edge crack location and propagation, thickness distribution in the flange, forming load and strain distribution. Experiments are conducted on double acting hydraulic press to validate the results of simulation for the same parameters and results show a very good relationship. In the passed a very less attention had been paid by the researchers in the area of fractography, i.e., the study of fractured surface. Second part of this investigation is fractography that is the study of fractured surface of sheet through field emission scanning electron microscopy (FESEM) and results are discussed in terms of size, shape and distribution of dimples on the cracked surface.

\section{Mechanical Properties of Material}

Tensile strength, elastic modulus and Poisson's ratio of aluminum alloy AA5052 sheet were obtained by tensile test on a computerized universal testing machine (UTM) by following the standard method, i.e., E8 ASTM (Tensile testing, 2nd edited by J.R. Davis, Davis \& Associates) [35]. This test was performed in the rolling direction of the sheet at a constant strain rate and at the room temperature under the normal atmospheric conditions. Data collected through the tensile test were used to prepare the true stress-true strain curve that is shown in Fig. 1. Tables 1 and 2 represent the mechanical properties and chemical composition of aluminum alloy AA 5052 sheet.

\section{Finite Element Modeling and Simulation}

Finite element simulation of stretch flanging process was carried out by using commercially available ABAQUS/ Explicit software. CAD model of a stretch flange is shown in Fig. 2. FE model, as shown in Fig. 3, was developed to

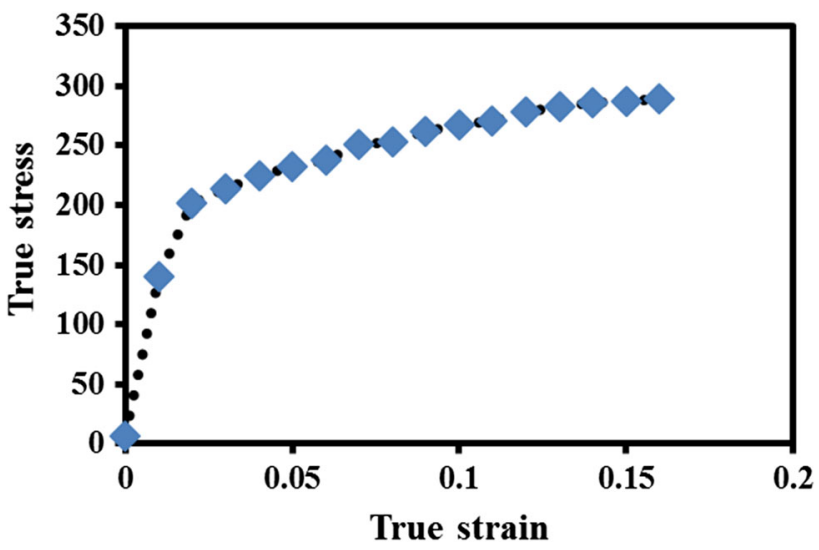

Fig. 1 True stress-true strain curve of AA 5052 [34]

Table 1 Mechanical material properties of AA-5052

Material properties (AA-5052)

Mass density $(\rho)$

$2680 \mathrm{~kg} / \mathrm{m}^{3}$

Young's modulus $(E)$

$70.3 \mathrm{GPa}$

Poisson's ratio $(v)$

0.33

Table 2 Chemical composition of aluminum alloy AA5052 (wt.\%) [36]

\begin{tabular}{lllllllllll}
\hline Composition & $\mathrm{Mg}$ & $\mathrm{Cr}$ & $\mathrm{Si}$ & $\mathrm{Fe}$ & $\mathrm{Mn}$ & $\mathrm{Cu}$ & $\mathrm{Zn}$ & total & $\mathrm{Al}$ \\
\hline Actual & 2.45 & 0.17 & 0.12 & 0.2 & 0.08 & 0.04 & 0.04 & 0.06 & Rest \\
\hline
\end{tabular}

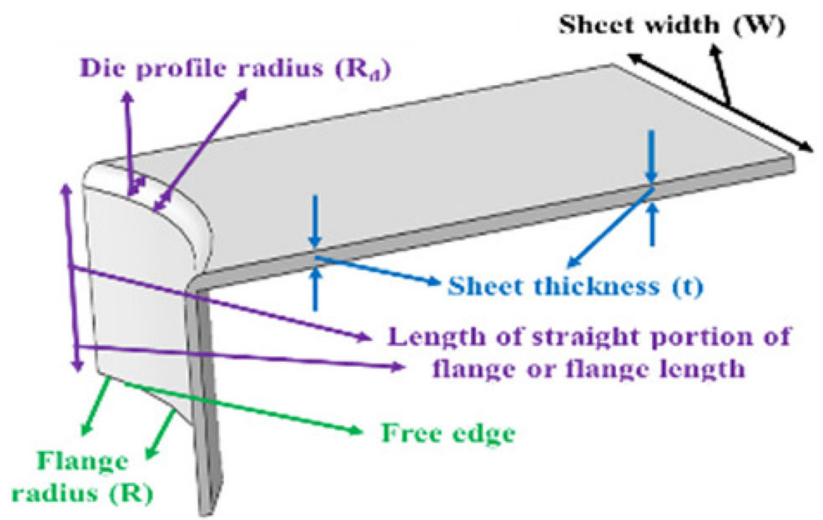

Fig. 2 A CAD model of stretch flange [34]

perform the stretch flanging simulation and to predict the crack initiation and propagation in the flange, strain distribution in the sheet along the die profile radius and to obtain the maximum forming load. In this, die was modeled with radius of 20,25,30 and $35 \mathrm{~mm}$ with the height of $60 \mathrm{~mm}$. The shape of the blank-holder was considered similar to the top surface of the die for better distribution of load and contact among the blank-holder, die and blank. In 
the simulation, die, blank-holder and punch were considered as rigid bodies and modeled with R3D4 element. R3D4 are rigid 3D four-nodded elements and formed the master surfaces during the contact definition conditions.

In the present study, a sheet metal blank of $120 \mathrm{~mm}$ in length, $30 \mathrm{~mm}$ in width and $0.5 \mathrm{~mm}$ in thickness was used for the flanging purpose. Width and thickness of the sheet were kept constant to investigate the effect of different die radius $(20,25,30$ and $35 \mathrm{~mm})$ on the stretch flanging process. Die radius and sheet thickness were kept constant to analyze the effect of blank width. Width of the blank was taken $20,25,30,35$ and $40 \mathrm{~mm}$ at a constant die radius of $35 \mathrm{~mm}$. Blank was prepared using three-dimensional C3D8R-elements, while S4R shell-type elements were used to analyze the thickness distribution in sheet for the parameters mentioned in Table 3. The C3D8R-element is one degree, continuum 3D eight nodded reduction integration, hexahedra solid element. The blank was considered as a deformable body and form the slave surfaces during contact definition condition. Clearance between the top surface of the die and the bottom surface of the sheet was kept at $0.1 \mathrm{~mm}$ to mitigate the penetration of sheet [37] in the die. In the rigid bodies, all boundary conditions were applied at a reference node that is defined on them. The die was fixed in all directions to define the stationary condition, whereas the movement of the punch takes place only in the z-direction to deform the blank and

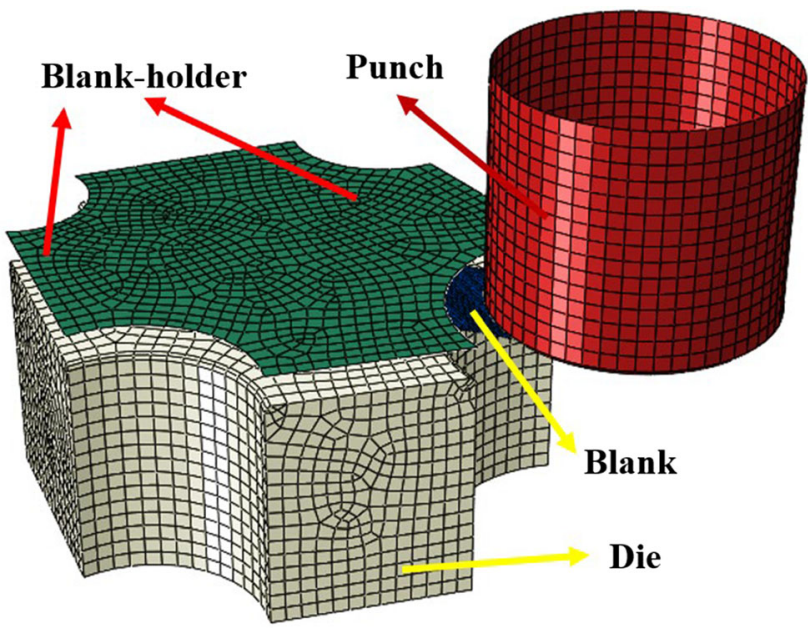

Fig. 3 FEM Model for stretch flanging process formed the flange. The blank material was assumed to behave as an elasto-plastic material with isotropic hardening. The constant blank-holding force of $20 \mathrm{kN}$ was applied on the blank-holder. The coefficient of friction between the contact surfaces was considered as 0.1 and the clearance of $1 \mathrm{~mm}$ was provided between the die and the punch $[1,2,38]$ in all cases. The parameters were chosen based on the published literature as mentioned in Table 3.

In simulation, the blank was fixed between the die and the blank-holder in such a way that $90 \mathrm{~mm}$ of the blank portion lies between the die and the blank-holder and remaining portion, i.e., $30 \mathrm{~mm}$ was kept free to deform and to get the final shape similar to the die profile. The free portion of the blank that deforms is called the flange length. The simulation process was carried out for the different parameters as mentioned in Table 3, and data were collected in terms of crack location, strain distribution etc. The simulated results were compared with the experimental results for the validation purpose.

Crack initiation and propagation were predicted by defining the ductile and the shear damage failure criteria based on the plastic strain conditions [37, 39-43]. Elements deletion technique was used for the damage evolution during stretch flanging process. Crack initiation takes place when the damage parameter $(D)$ reached to 1 [37].

\section{Experimentation of Stretch Flanging Process}

The $50 \mathrm{kN}(30 \mathrm{kN}+20 \mathrm{kN})$ double acting hydraulic press equipment with a load cell was used to carry out the experiment of stretch flanging process and results were used to validate the simulation results. Figure 4 shows the tool setup of stretch flanging process with the punch, the die, the blank-holder and the sheet. Different parameters in experiment were kept similar to FE simulation as mentioned in Table 3. Die and punch were made of mild steel with well-polished surfaces. Blank was placed between the die and the blank-holder and tightened firmly by bolts. Free portion and the clamped portion of the sheet were kept similar to the FE simulation. $1 \mathrm{~mm}$ of clearance was maintained between the die and the punch, and filler gauge was used to measure the clearance. Experiments were performed at the room temperature, and the blanks were used without annealing. Lubricant was not used among the

Table 3 Parameters used in FE simulation and experimental work

\begin{tabular}{lll}
\hline S. No. & \multicolumn{1}{c}{ Parameter } & \multicolumn{1}{c}{ Value considered in FE simulation and experimental } \\
\hline 1. & Die radius $(\mathrm{mm})$ & Die radius of 20, 25, 30 and $35 \mathrm{~mm}$ at constant sheet width of $30 \mathrm{~mm}$ \\
2. & Sheet width $(\mathrm{mm})$ & $\begin{array}{l}\text { Sheet width of 20, 25, 30,35 and } 40 \mathrm{~mm} \text { at constant die radius of } \\
35 \mathrm{~mm}\end{array}$ \\
\hline
\end{tabular}


Fig. 4 Double acting hydraulic press and tool setup

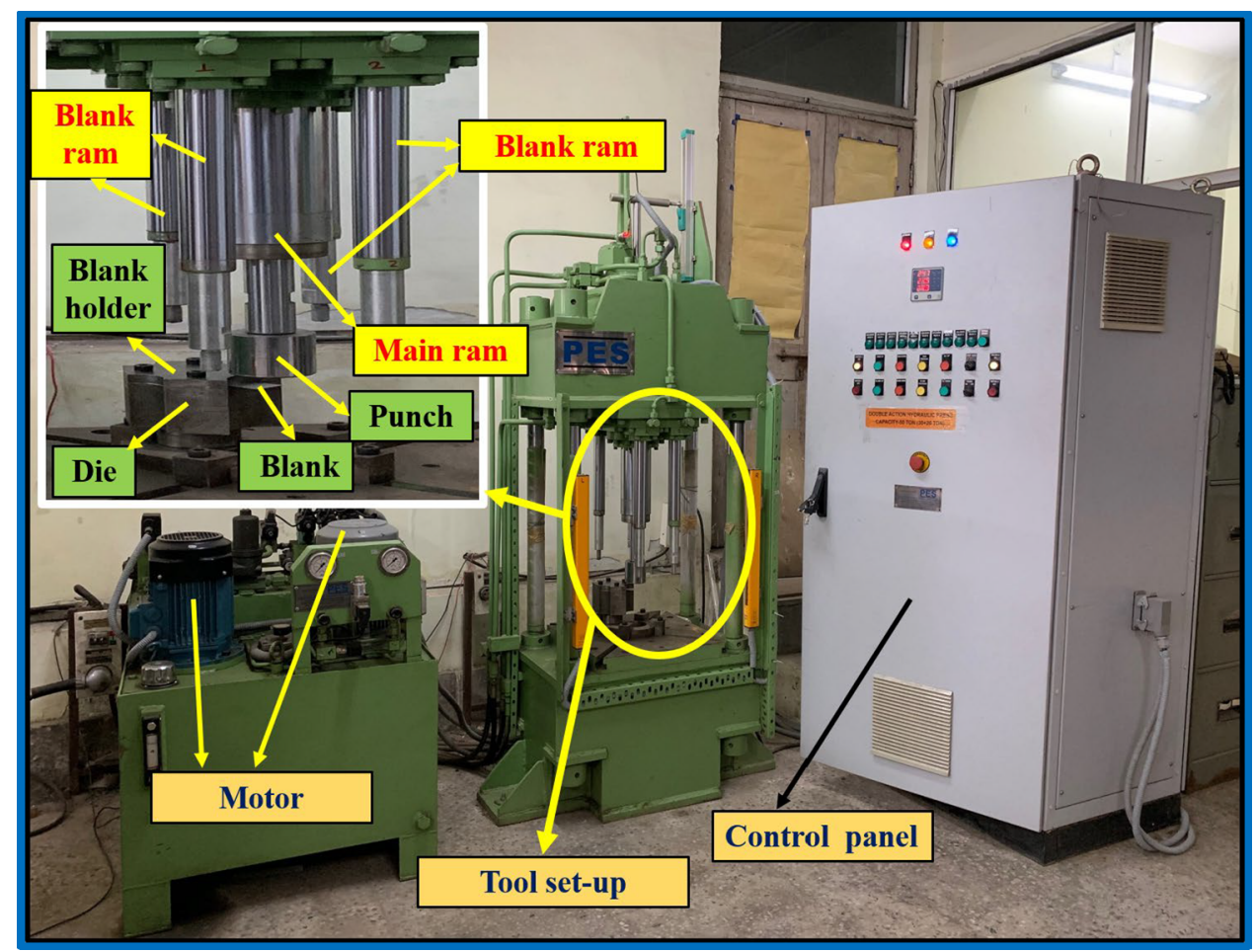

die, blank, blank-holder and punch. Downward movement speeds of the punch were fixed at $25 \mathrm{~mm} / \mathrm{s}$ until the punch reaches for a certain distance or just makes a contact with the blank. Punch speed of $1 \mathrm{~mm} / \mathrm{s}$ was controlled with the help of a computerized control panel. After completion of deforming process, forming load was released by defining the punch movement in upward direction and data were recorded in the system. The schematic diagram of the process is shown in Fig. 4. The flange, with the final shape, was taken out from the tool setup to measure the crack length and thickness of the sheet.

Fractography of the final product were carried out by field emission scanning electron microscopy (FESEM) to depict the fracture modes for different die radius and sheet width. Different forces like tensile, compressive, bending and shearing generate during stretch flanging process. Any failure occurs during the forming depends on the type of forces or combination of these forces and it affects the size and the shape distribution of the dimples on fractured surface.

\section{Analysis of the Bending Force}

The maximum bending force can be determined by using the following equation $[1,2]$

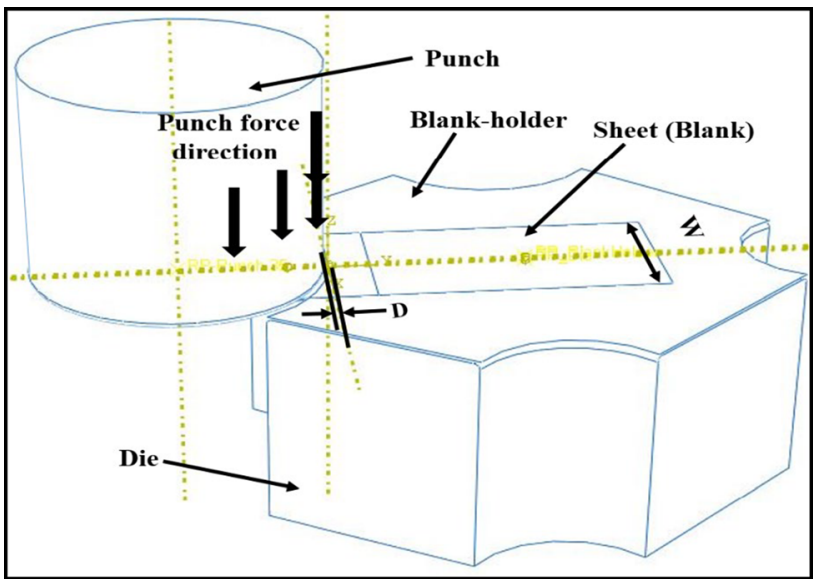

Fig. 5 Schematic diagram of tool setup for the assessment of bending force

Maximum bending force $(F)=\left(\frac{K_{\mathrm{bf}} *(\mathrm{TS}) * W * t^{2}}{D}\right)$

where $K_{\mathrm{bf}}=$ constant factor which depends on the types of bending process $\left(K_{\mathrm{bf}}=0.33\right.$ for edge bending and $K_{\mathrm{bf}}=$ 0.7 for $\mathrm{U}$ type bending), $t=$ sheet thickness, $W=$ sheet width, TS $=$ Tensile strength of the materials, $D=$ die opening dimension (span length). The schematic diagram for assessment of bending force of stretch flanging process is shown in Fig. 5. 


\section{Results and Discussion}

Validation of the Simulation Results

Simulation results were compared with the experimental results in terms of crack length, edge crack location and its propagation with respect to punch displacement.

\section{Effect of Sheet Width}

Sheet width is an important parameter which affects the deformation behavior of sheet in stretch flanging process. Deformation pattern of the Al material sheet is shown in Figs. 6 and 7. Al alloy 5052 sheets of different width were used to minimize the edge crack length along the die

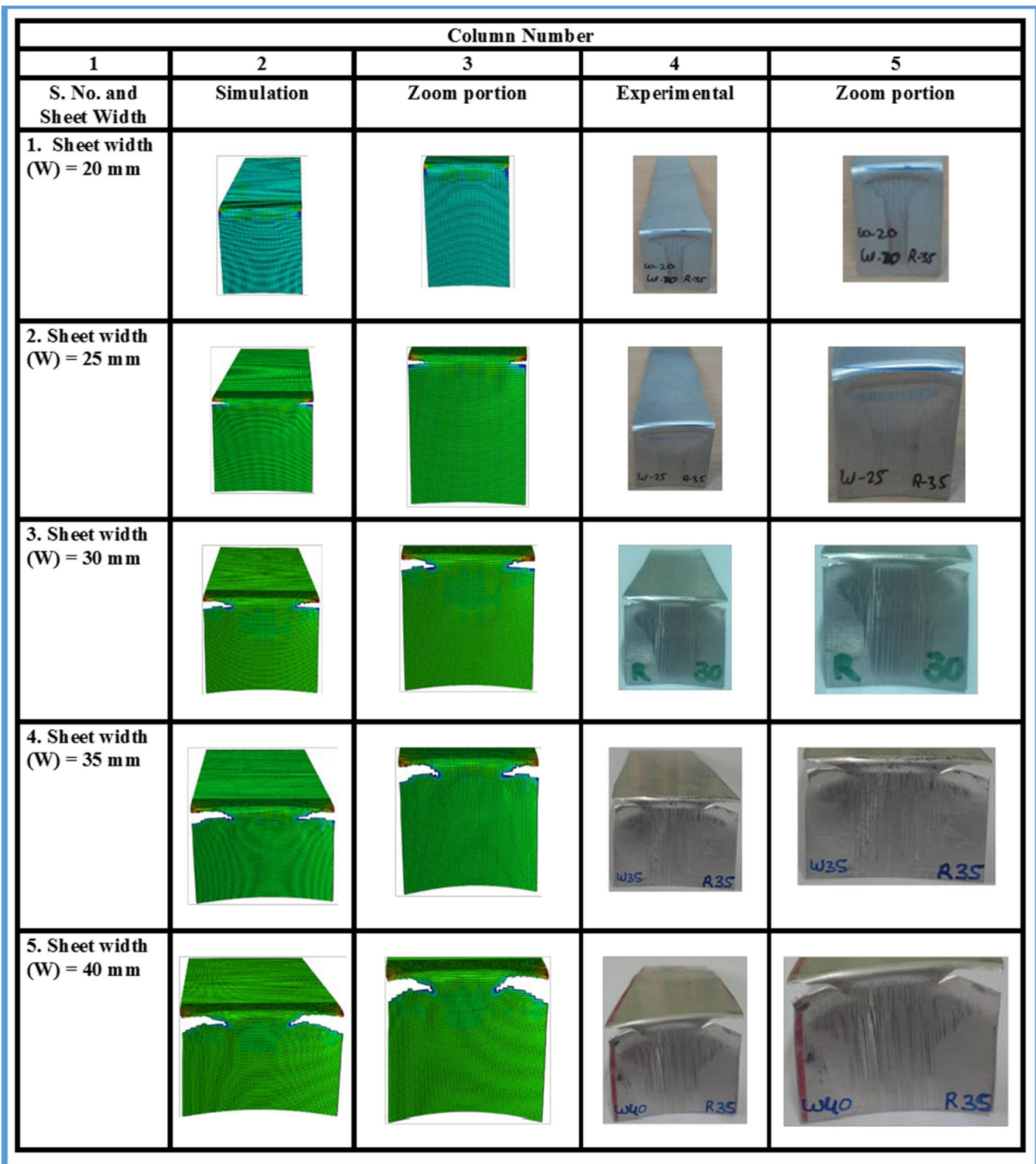

Fig. 6 Comparison of crack length for different sheet width $(20,25,30,35$ and $40 \mathrm{~mm})$ at $35 \mathrm{~mm}$ die radius 
Fig. 7 Comparison of crack length for different sheet width $(25,30,35$ and $40 \mathrm{~mm})$ at $35 \mathrm{~mm}$ die radius

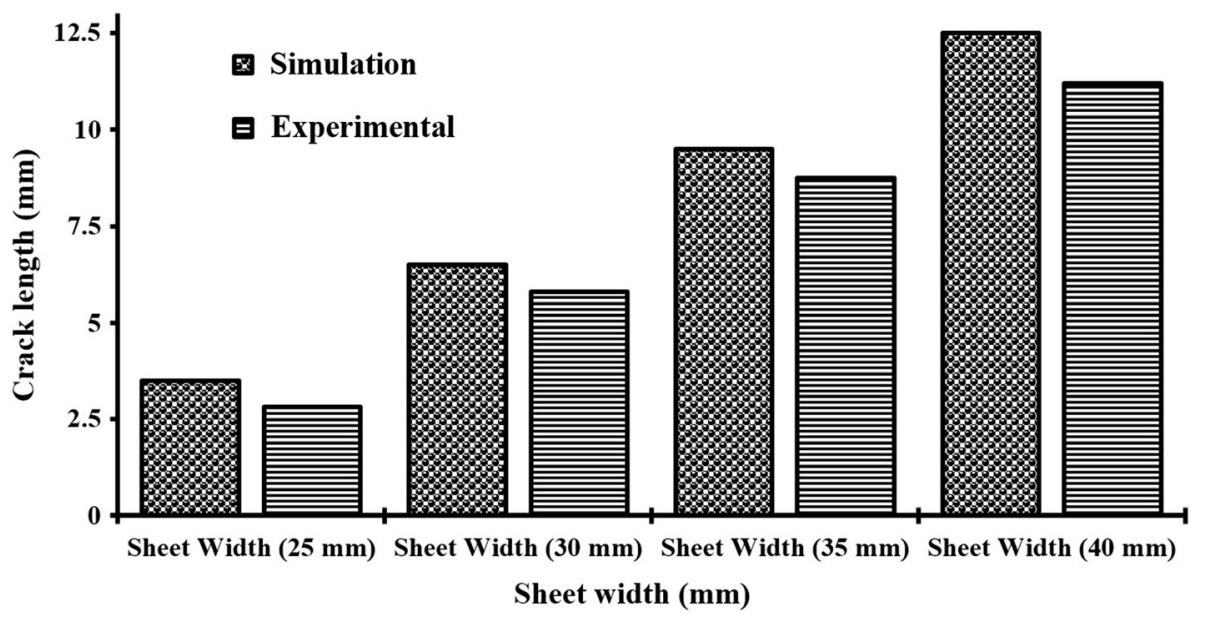

Fig. 8 Comparison of reduction in thickness of sheet for different sheet width $(25,30$, 35 and $40 \mathrm{~mm}$ ) at constant die radius of $35 \mathrm{~mm}$

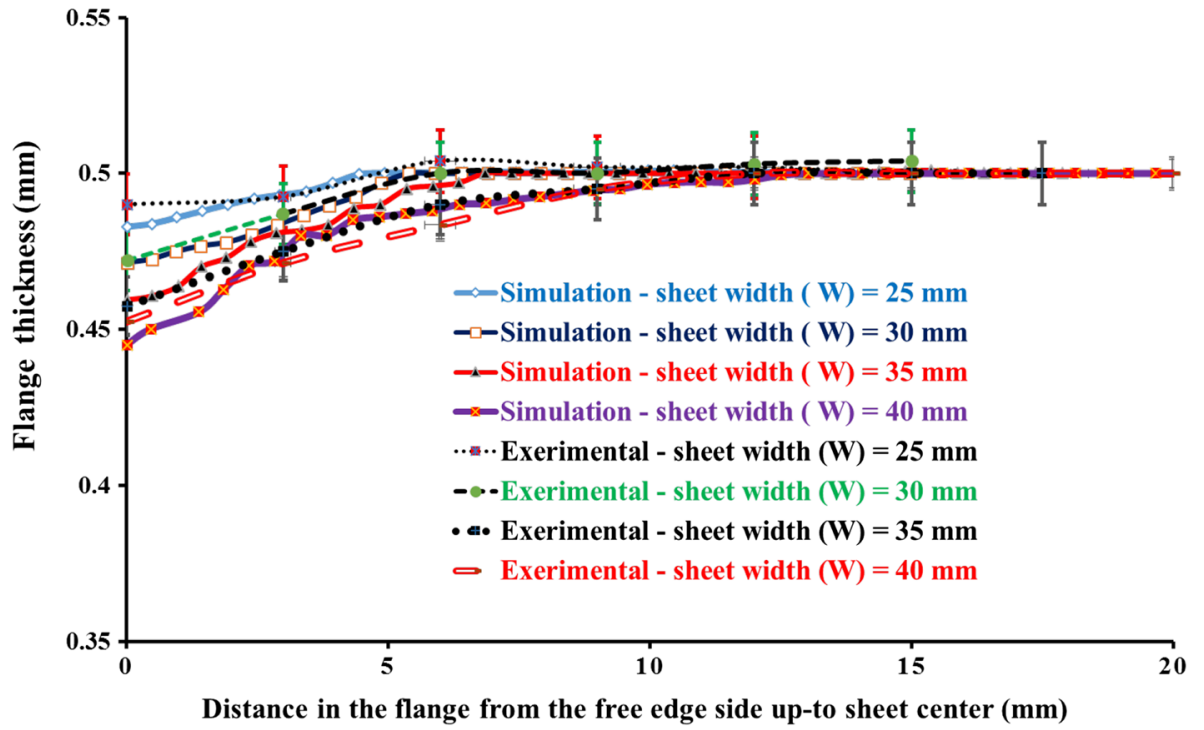

profile radius. The final shape of the deformed sheet by FEM simulation is shown in columns 2 and 3, while the experimental results are shown in columns 4 and 5 of Fig. 6. Initiation of crack takes place from both corners along the die profile radius and propagates toward the center of the sheet in all cases. The crack contours observed in FE simulation are found similar to the experimental one. The crack length in simulated results was measured with the help of the query information tools available in ABAQUS/Explicit software while in experiments it was measured by using digital Vernier calipers with a least count of $0.01 \mathrm{~mm}$. According to the figures, crack length in sheet increases with increase in sheet width. It indicates that the deformability of the sheet reduces with increase in sheet width. Edge crack length is found maximum when width of sheet is $40 \mathrm{~mm}$, i.e., maximum. The reason of increase in crack length with increase in sheet width may be due to the higher friction between the tools and the blank. It also results in increase in bending force which is directly proportional to the sheet width as given in Eq 1. It is clear from Eq 1 that large forming load is required to bend the sheet of high width [1, 2]. Crack length was found minimum for $25 \mathrm{~mm}$ sheet width. Therefore, crack length decreases in simulation as well as in experiments. However, the flange of proper concave shape without fracture could not be achieved at any width of sheet. For $20 \mathrm{~mm}$ sheet width, flange is formed without concave shape. In this condition, it behaves like a straight flanging process and considerable spring back is found. Hence, formability of flange of concave shape reduces for the sheet width less than $20 \mathrm{~mm}$.

Figure 8 shows the variation in thickness of sheet for different sheet width at constant die radius of $35 \mathrm{~mm}$. Reduction in thickness is measured by defining the meridian path-2, as shown in Fig. 9, which is considered near to edge crack position along the die profile radius. A 
Fig. 9 Path-1, considered for circumferential and radial strain near the crack and Path-2, considered for measuring the thickness of sheet

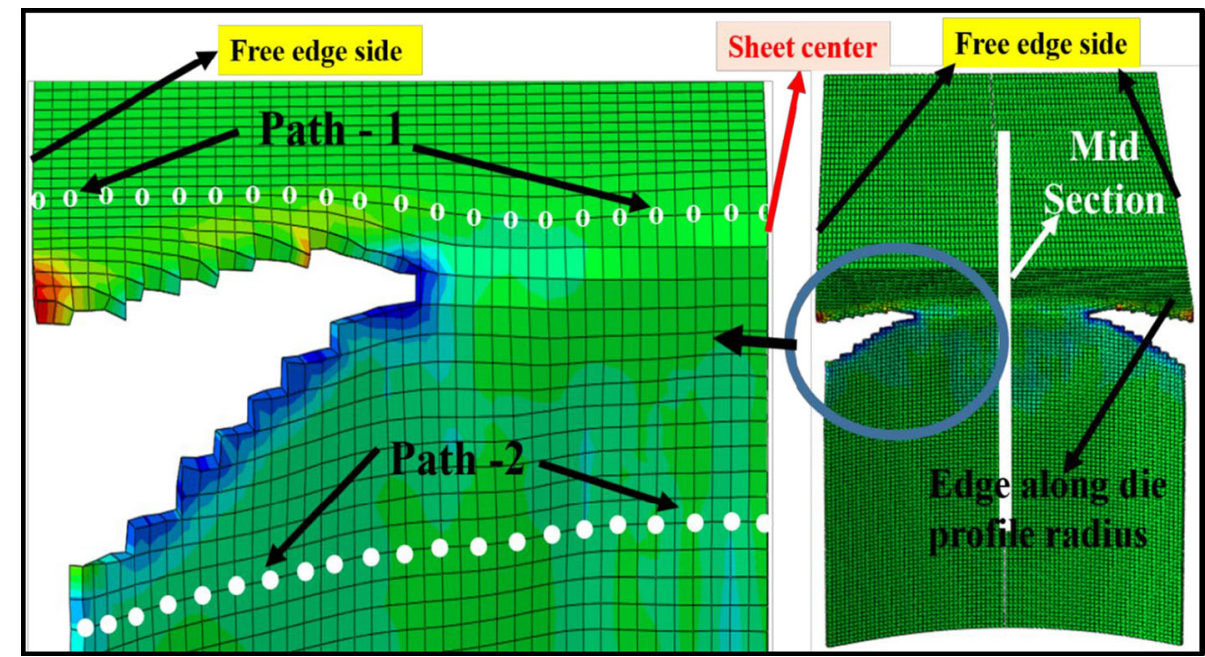

Fig. 10 Contour plots for sheet thickness distribution for different sheet width $(25,30,35$ and $40 \mathrm{~mm}$ ) at constant die radius of $35 \mathrm{~mm}$ by FEM simulation

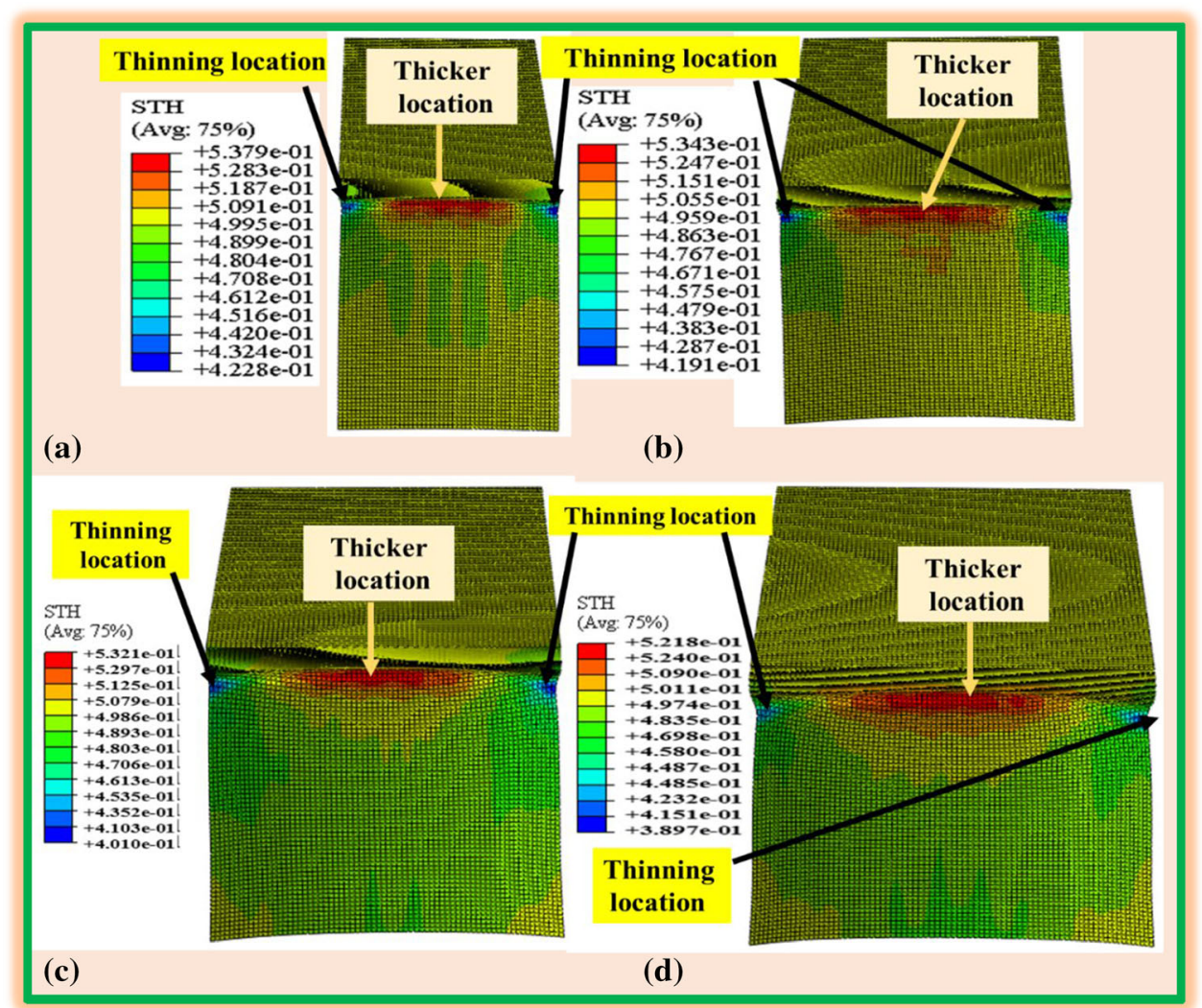

graph is plotted between the flange thicknesses with respect to distance between free edge of the flange to the center of the deformed blank. The maximum reduction in thickness is obtained when larger sheet width is used whereas it is found minimum for smaller sheet width. Comparison of simulation and experimental results is shown in Figs. 8 and 10.

\section{Effect of Die Radius}

Die radius is also an important parameter which affects the edge crack length and edge crack propagation in stretch flanging process. In the present study, different die radii were used at constant sheet width for studying the deformation behavior of sheet and failure of flange in the form 


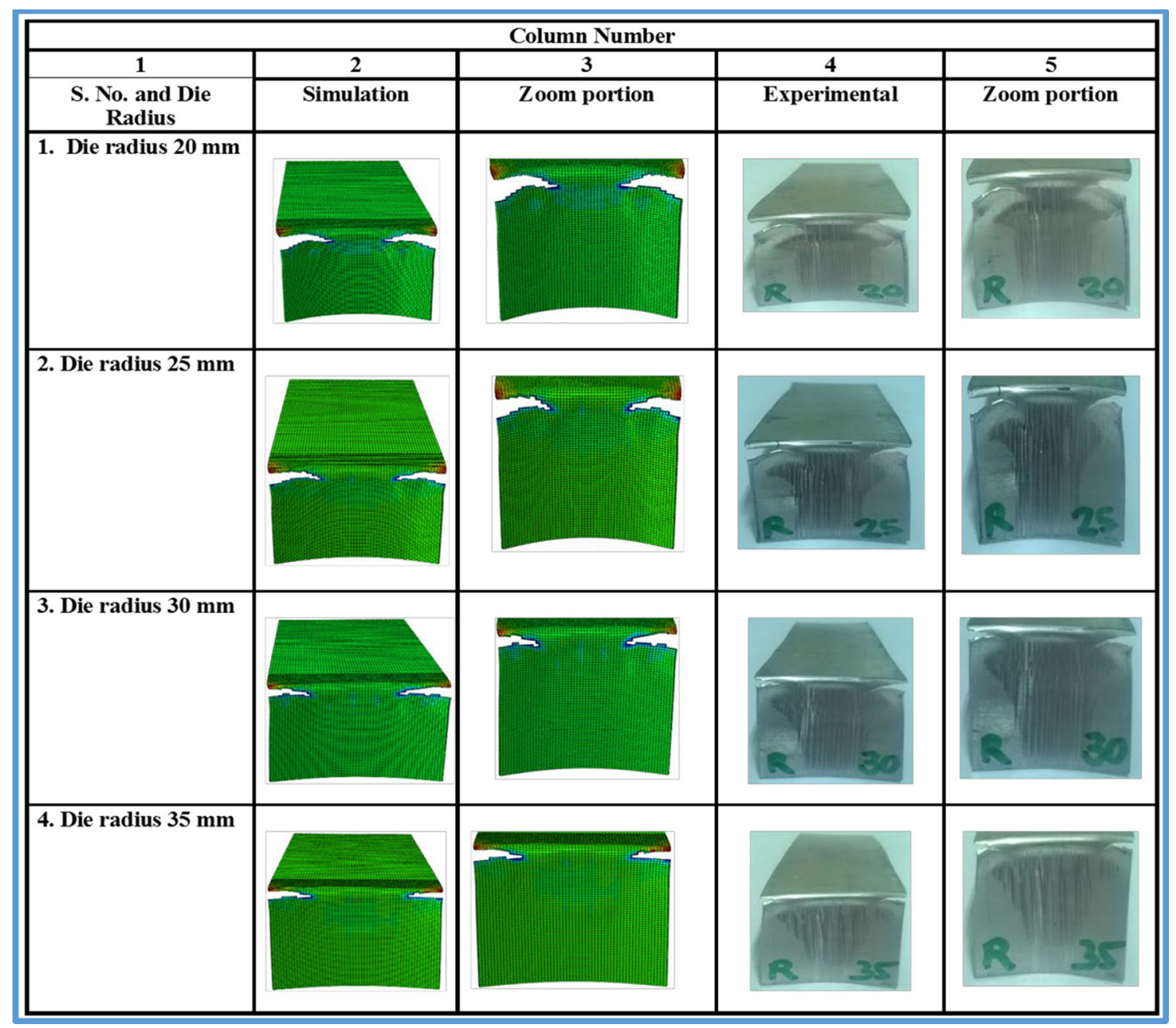

Fig. 11 Comparison of crack length for different die radius $(20,25,30$ and $35 \mathrm{~mm})$ at constant sheet width of $30 \mathrm{~mm}$ by FEM simulation and experimental results

Fig. 12 Comparison of crack length for different die radius $(20,25,30$ and $35 \mathrm{~mm})$ at constant sheet width of $30 \mathrm{~mm}$ by FEM simulation and experimental results

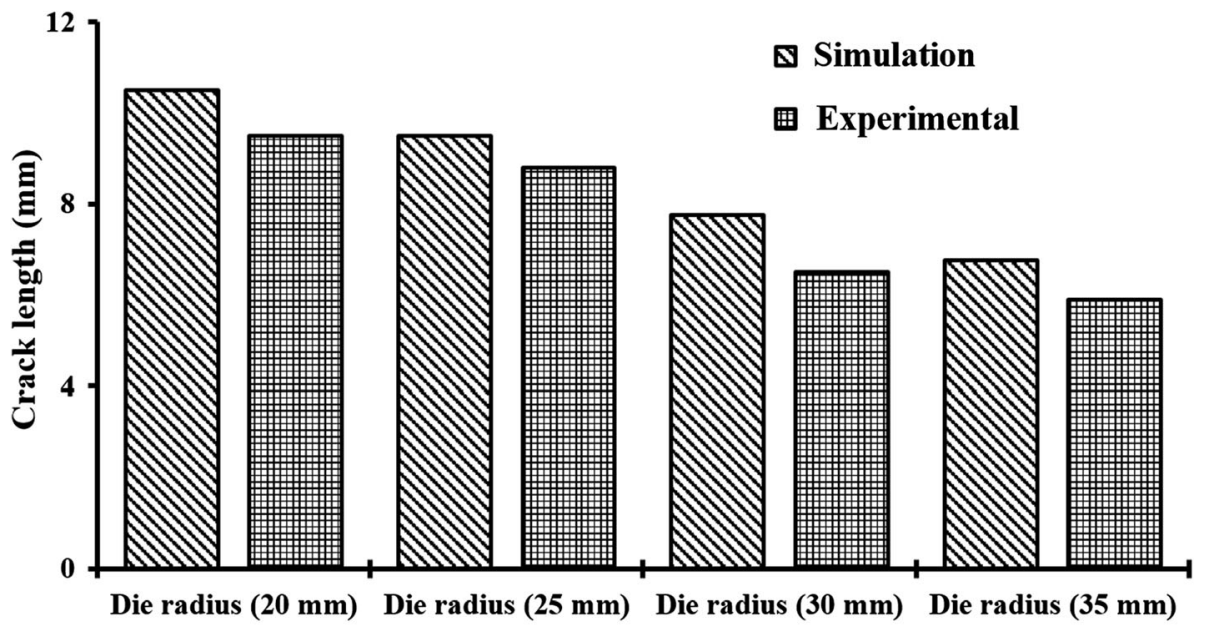

Die radius (mm) 
of crack length and its propagation. The final shapes of the stretch flange with crack after forming are shown in Fig. 11. The crack initiation takes place along the die profile radius and propagates toward the sheet center up to some extent. Columns 2 and 3 in Fig. 11 show the FEM simulation results, while the columns 4 and 5 represent the experimental results at lower as well as at higher

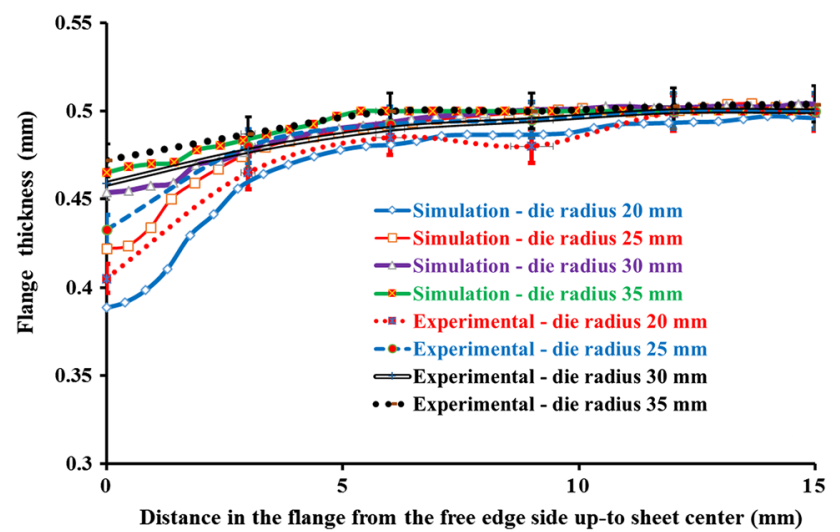

Fig. 13 Comparison of reduction in thickness of sheet for different die radius $(20,25,30$ and $35 \mathrm{~mm})$ at constant sheet width $(30 \mathrm{~mm})$ magnification. The procedure of measuring the crack length in FE simulation and in experiments is identical to the procedure adopt in measuring the effect of sheet width section. Figure 12 shows the comparison of maximum crack length for various die radiuses. It can be easily seen from Fig. 12, that maximum edge crack length is found in $25 \mathrm{~mm}$ die radius, whereas minimum in $35 \mathrm{~mm}$ die radius by simulation as well as by experimentation. Hence, it can be concluded that crack length increases with decrease in die radius. It may be due to a smaller amount of stress concentration in the sheet at higher die radius due to sufficient space is available for deformation of sheet. It might be due to the reduction in friction force also with increase in curvature of die radius. Hence, forming load also reduces in these conditions.

Variation of thickness in sheet is also measured for different die radius at constant sheet width. A graph is plotted between the flange thickness and the distance between free edge of the flange to the center of the deformed blank and it is shown in Fig. 13. It can be seen from figure that maximum thinning is occurs when smaller die radius is used as shown in Figs. 13 and 14. These results are validated with experimental one and found in very good agreement.
Fig. 14 Contour plots for sheet thickness variation for different die radius (a) $20 \mathrm{~mm}$ (b) $25 \mathrm{~mm}$ (c) $30 \mathrm{~mm}$ (d) $35 \mathrm{~mm}$ at constant sheet width of $30 \mathrm{~mm}$ by FE simulation

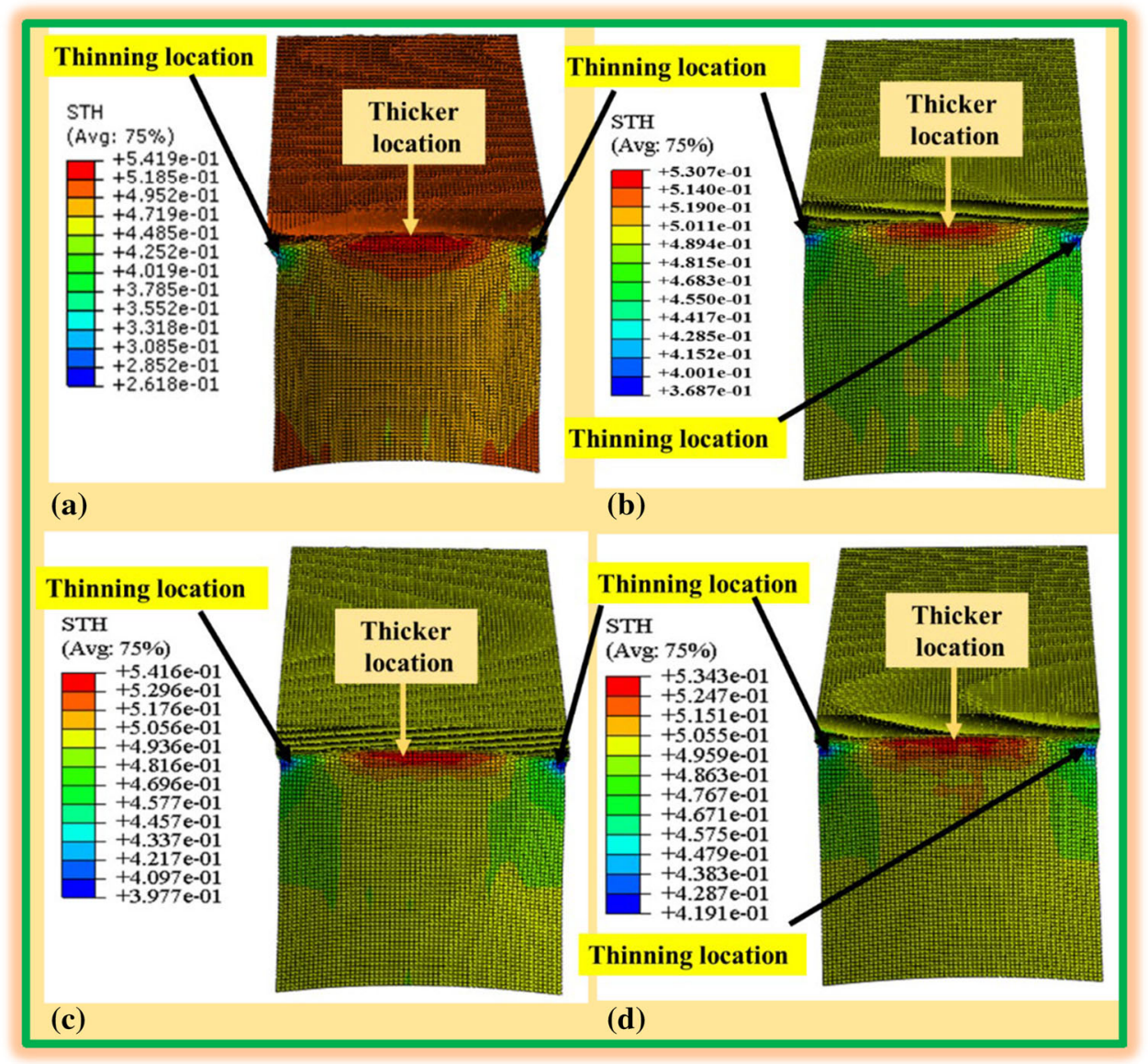




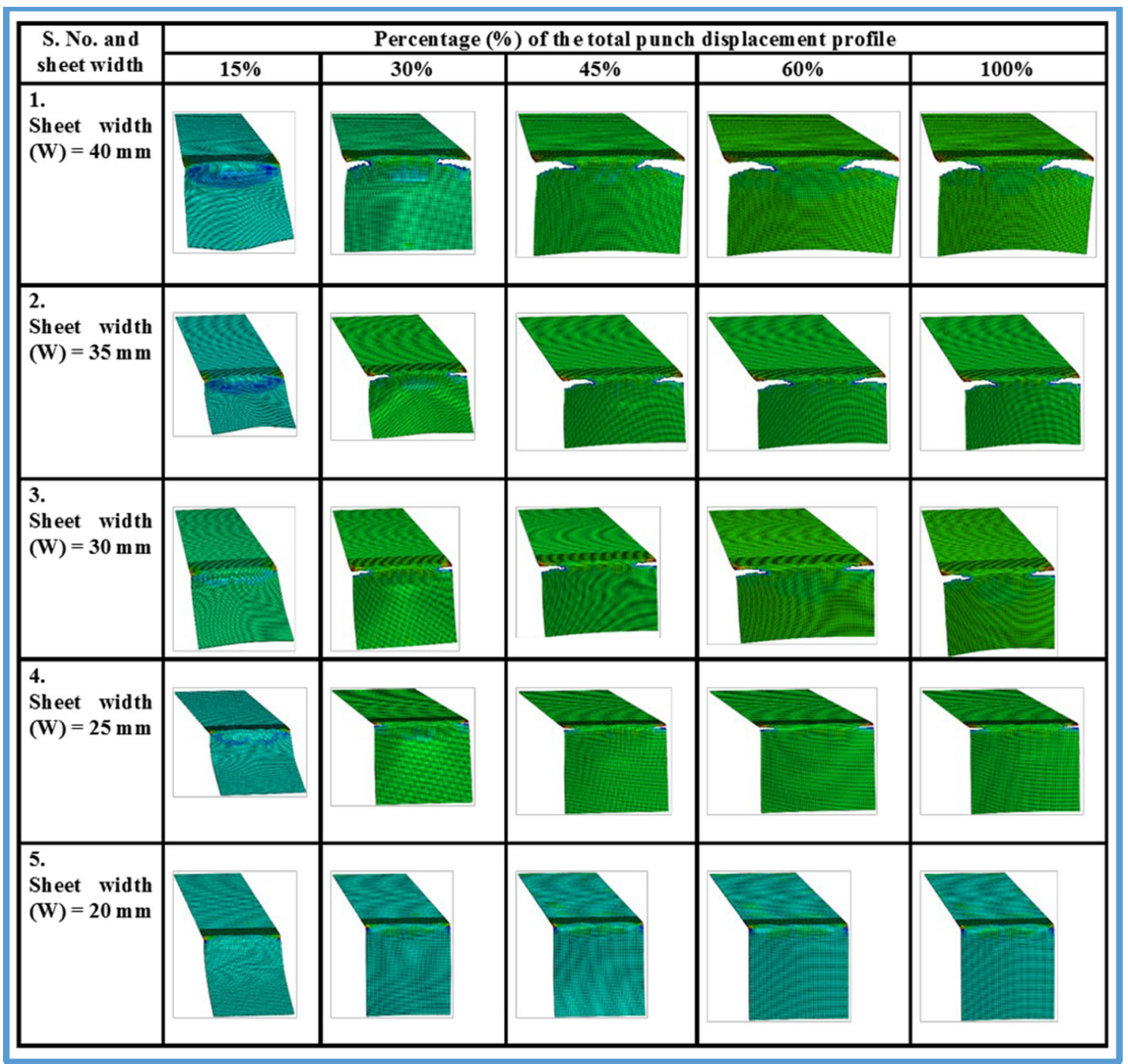

Fig. 15 Deformed shape of sheet at different percentage of punch displacement by FEM for different sheet width at constant die radius of $35 \mathrm{~mm}$

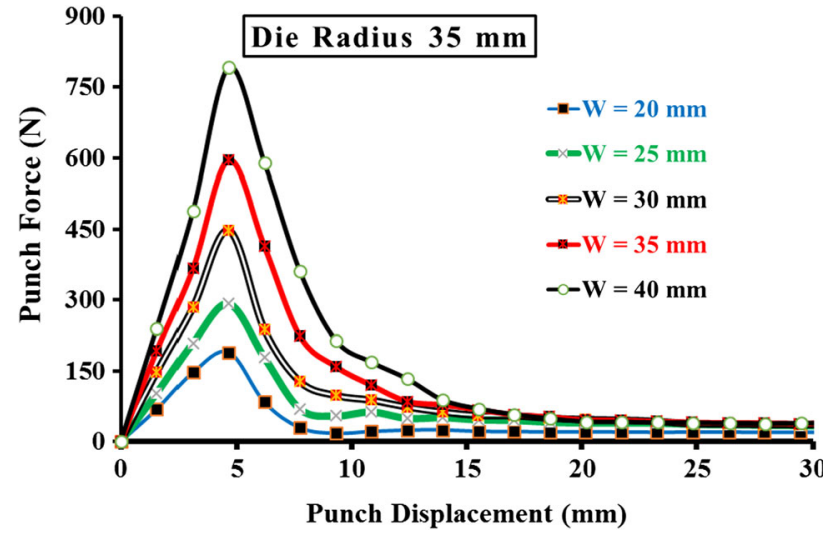

Fig. 16 Influence of sheet width on punch load at different sheet (20, $25,30,35$ and $40 \mathrm{~mm}$ ) at constant die radius of $35 \mathrm{~mm}$ by $\mathrm{FE}$ simulation

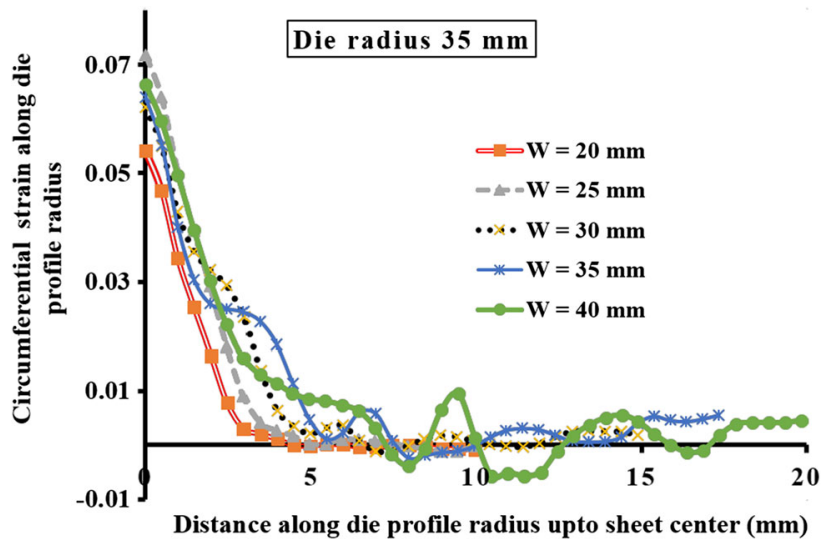

Fig. 17 Influence of sheet width on circumferential strain at different sheet width $(20,25,30,35$ and $40 \mathrm{~mm})$ at constant die radius of $35 \mathrm{~mm}$ by FE simulation 


\section{FEM Simulation Results}

\section{Effect of Sheet Width}

In this study, effect of the sheet width and the die radius on deformation behavior of sheet was investigated. The sheet width is one of the significant parameter in stretch flanging process that affect the deformation behavior of the sheet.

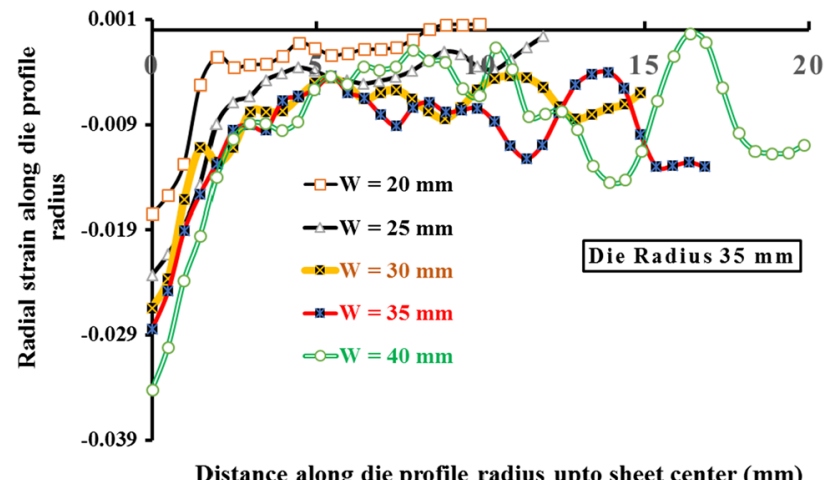

Fig. 18 Influence of sheet width on radial strain at different sheet width $(20,25,30,35$ and $40 \mathrm{~mm})$ at constant die radius of $35 \mathrm{~mm}$ by FE simulation
Figure 15 shows the deformed shape of the sheet for different width at $15,30,45,60$ and $100 \%$ of the total punch displacement. From Fig. 15, it is observed that the crack starts probably after $30 \%$ of the total punch displacement in all cases. No crack is observed at any \% of punch displacement in the case of $20 \mathrm{~mm}$ sheet width with $35 \mathrm{~mm}$ of die radius because this combination behaves like a straight flanging process. Therefore, it is found that sheet width of $20 \mathrm{~mm}$ with die radius of $35 \mathrm{~mm}$ should not be use in stretch flange forming. Crack length and deformations are also observed different for different sheet width at constant die radius. It can be seen from Fig. 15 that the crack length increases with increase in sheet width and better stretching and minimum crack length is observed at 30 to $35 \mathrm{~mm}$ sheet width with $35 \mathrm{~mm}$ die radius.

A graph is plotted between the punch load and the punch displacement for different sheet width is shown in Fig. 16. Forming load increases with advancement in punch displacement up to a certain distance $(5 \mathrm{~mm})$ and reached at its maximum value. The reason of increased forming load is due to the resistive capability of the sheet in unbend position (elastic deformation limit). When the sheet deform up to a certain angle then forming load decreases

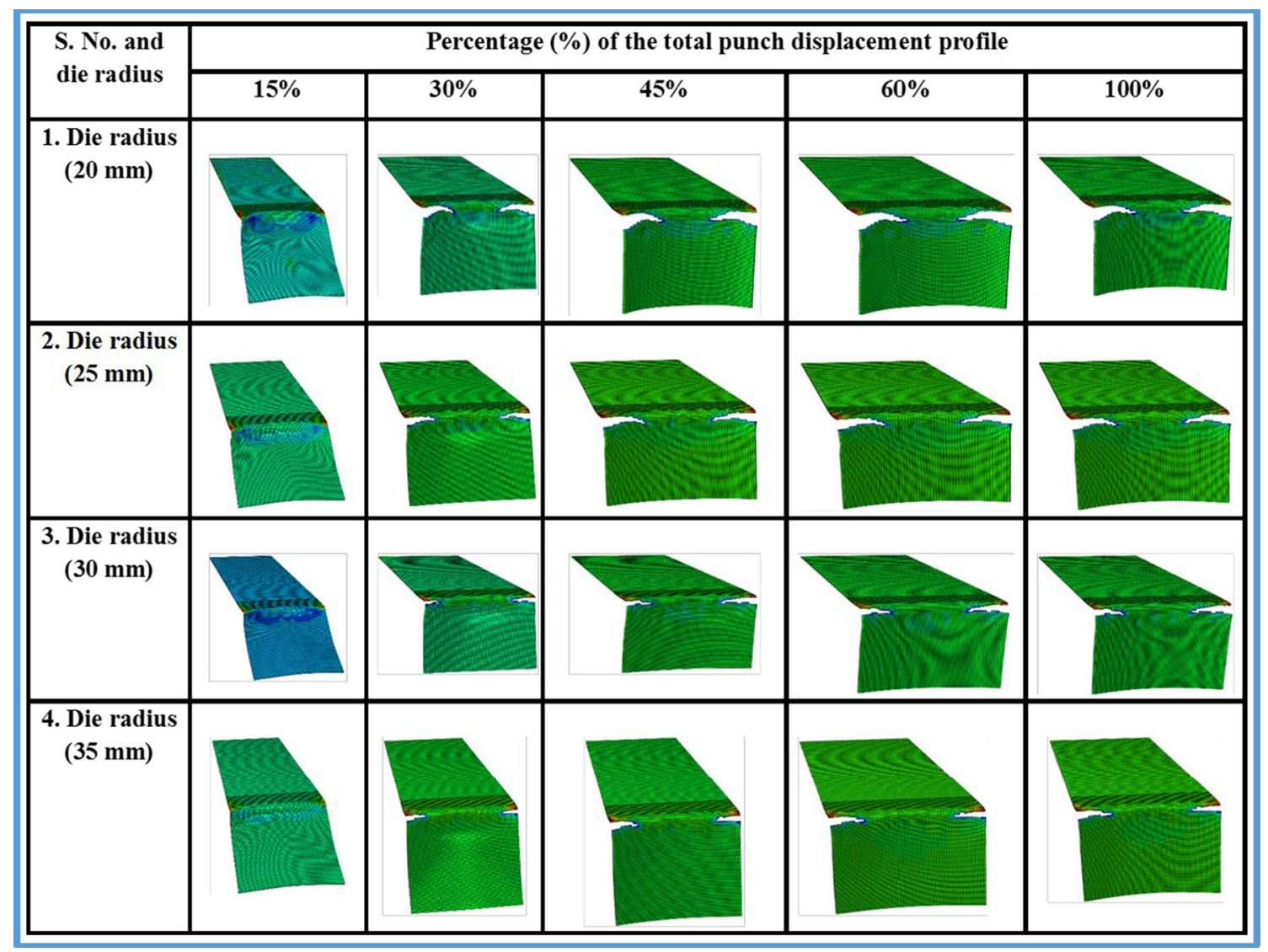

Fig. 19 Deformed shape of sheet at different percentage of punch displacement by FEM for different die radius at constant sheet width of $30 \mathrm{~mm}$ 


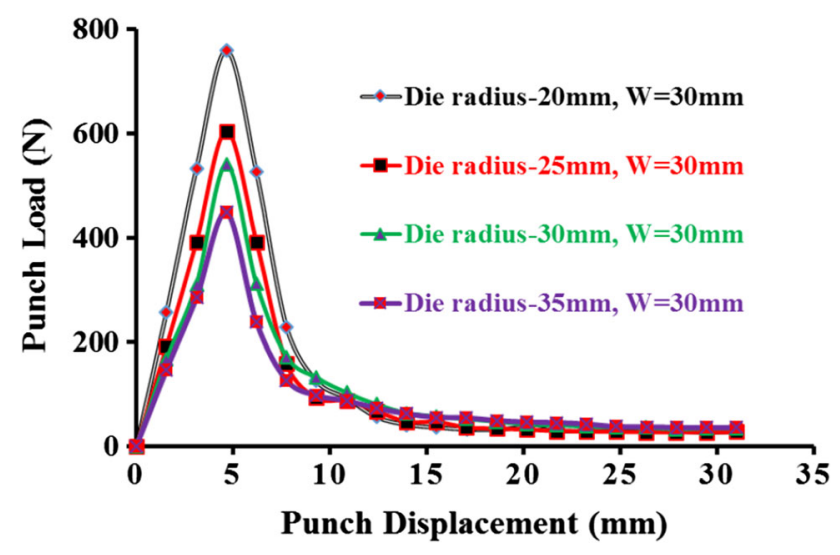

Fig. 20 Influence of die radius on punch load at different die radius $(20,25,30$ and $35 \mathrm{~mm})$ at constant sheet width $30 \mathrm{~mm}$ by FE simulation

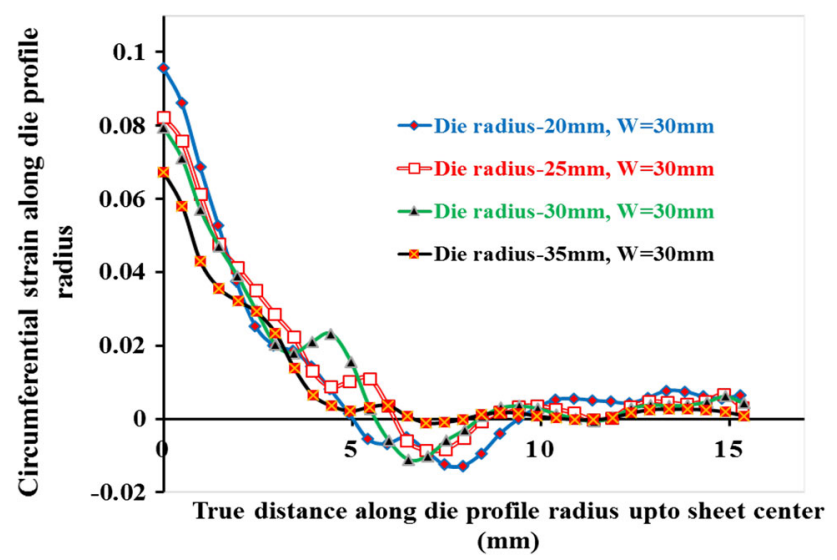

Fig. 21 Influence of die radius on circumferential strain at different die radius $(20,25,30$ and $35 \mathrm{~mm})$ at constant sheet width $30 \mathrm{~mm}$ by FE simulation

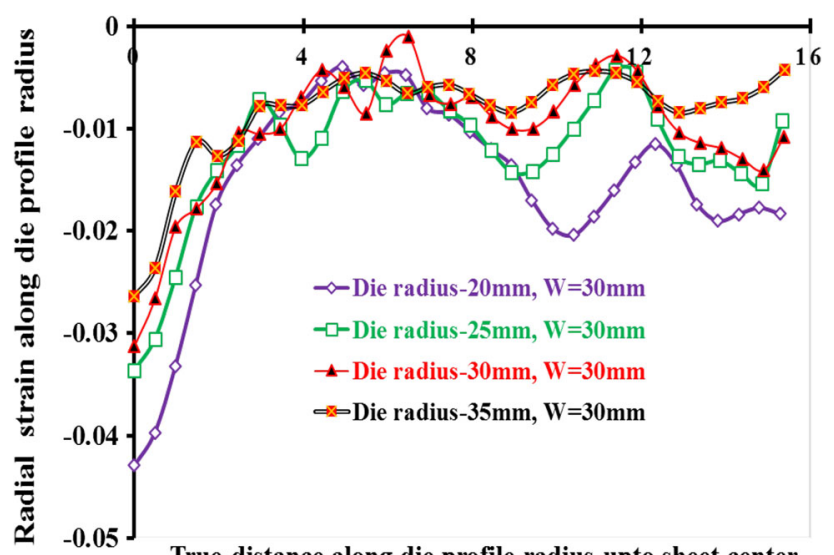

(mm)

Fig. 22 Influence of die radius on radial strain at different die radius $(20,25,30$ and $35 \mathrm{~mm})$ at constant sheet width $30 \mathrm{~mm}$ by FE simulation prominently because of the crack propagation that reduces the resistive capacity of the sheet. After a definite bend angle, punch slides over the sheet that result in decrease in the forming load. The sliding of the punch starts after the $5 \mathrm{~mm}$ punch displacement, approximately, which result in decrease in punch load sharply and then it remains constant for the entire punch displacement. It is also observed that punch load decreases with decrease in sheet width and it may be due to the friction between the blank and the tool interface. Therefore, the higher forming load is required to bend a blank of larger sheet width (40 mm sheet width). Results are also found in the line of bending Eq $1[1,2]$, whereas less forming load is required for $20 \mathrm{~mm}$ sheet width. It may be due to the less friction between the tool and sheet $[1,2]$. The maximum forming load increases approximately $76 \%$ with increase in sheet width from $20 \mathrm{~mm}$ to 40 .

Sheet width also influences the circumferential and the radial strain distribution in stretch flanging operation. The strain distribution was predicted in the deformed blank by drawing the meridian path that was selected very near to edge crack point along the die profile radius as shown in Fig. 8. A graph is plotted between the circumferential strain with respect to distance along die profile radius up to the deformed sheet center for all cases as shown in Fig. 17. Figure 18 shows the graph of the radial strain with respect to distance along die profile radius up to the deformed sheet center for all sheet width. The maximum circumferential and the radial strain are found in larger sheet width, i.e., $40 \mathrm{~mm}$ because maximum friction between the blank and tool interface takes place that results in more stretching of sheet circumferentially. Whereas, a reverse condition was observed for the smaller sheet width because it behaves like a straight flanging deformation with large die radius. It also reduces the stress concentration in unit area of the material $[1,2]$. The maximum circumferential and the radial strain occur at edge portion of the flange and decreases toward the center of the sheet along the die profile radius as shown in Figs. 17 and 18. These are found minimum at mid-section of deformed sheet. The circumferential strain, radial strain and edge crack propagation increases with the increase in sheet width. Increment in circumferential and radial strain is observed 23 and $48 \%$, respectively when the sheet width increases from 20 to $40 \mathrm{~mm}$.

Influence of Die Radius

Figure 19 shows the deformed shape of the sheet at different percentage of total punch displacement, i.e., 15, 30, 45,60 and $100 \%$ for different die radii at the constant sheet width. Crack initiated nearly at $30 \%$ of the total punch 
Fig. 23 Fractographs of following die radius (a) die radius $20 \mathrm{~mm}$ (b) die radius $25 \mathrm{~mm}$ (c) die radius $30 \mathrm{~mm}$ and (d) die radius $35 \mathrm{~mm}$, at constant sheet width of $30 \mathrm{~mm}$
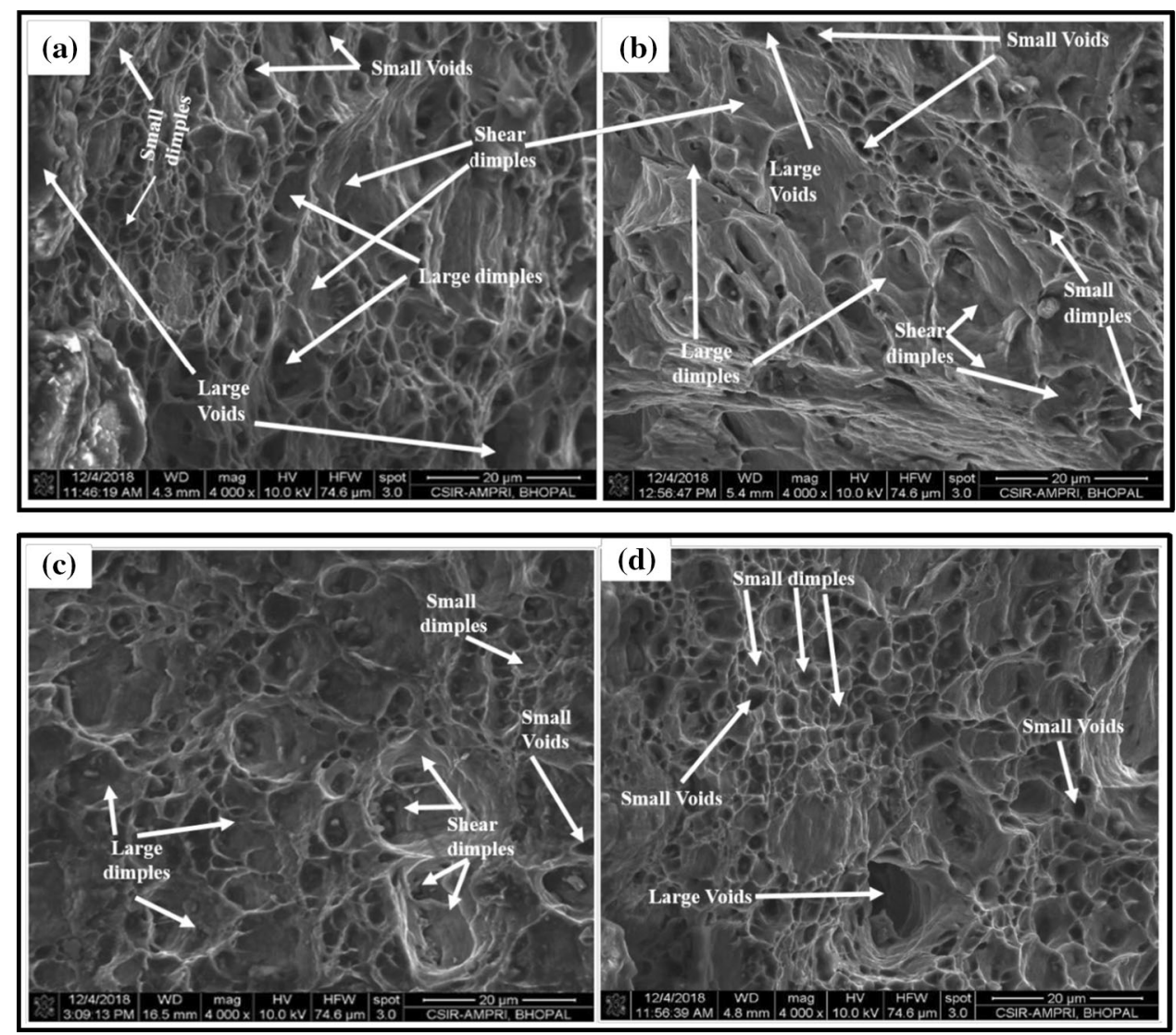

displacement in all cases. Deformation of sheet in stretch flanging process is also affected by the die radius for the same size and shape of the blank that can be seen from Fig. 19. The crack length decreases with increase in the die radius and deformation of sheet also reduces due to the large radius of curvature of the die. The maximum crack length is found for $20 \mathrm{~mm}$ die radius, while the minimum crack length is observed at $35 \mathrm{~mm}$ die radius. It can be concluded from this that if the sheet width is used nearly to $30 \mathrm{~mm}$ with 25 to $30 \mathrm{~mm}$ die radius, it provides better deformability of the sheet.

Figure 20 shows punch load v/s punch displacement graph for different die radius. The variation in punch load is found similar to the sheet width variation. The forming load decreases with increase in die radius because of less curvature of die radius and availability of more suitable space for deformation of the sheet as shown in Fig. 20. It can be seen from figure that maximum forming load is required to deform the sheet when die radius is small or due to large curvature of die. On the other hand, forming load requirement is minimum for the large die radius ( $35 \mathrm{~mm}$ die radius). The maximum forming load decreases approximately $25 \%$ with increase in the die radius from 25 to $35 \mathrm{~mm}$.

Figures 21 and 22 represent the graph of circumferential and radial strains for all die radii. It can be seen from
Figs. 21 and 22 that the maximum radial as well as the circumferential strain occurs near to the edge of the flange along to the die profile radius, while it decreases toward the center. Circumferential and radial strain decreases with increase in die radius because of reduction in the stress concentration due to the less curvature of die radius and sufficient space available for deformation of sheet. Decrements in circumferential and radial strain are found 29.63 and $38.46 \%$, respectively, when increase in the die radius from 20 to $35 \mathrm{~mm}$.

Fractography of AA5052 Alloy Sheets After Stretch Flanging Process

Fractographs of samples has been analyzed from the FESEM fracture micrographs at 4000 magnifications for each test. Figure 23 shows the fractured surfaces of AA5052 aluminum alloy sheet after the stretch flange forming at different die radius 20, 25, 30 and $35 \mathrm{~mm}$ having constant sheet width of $30 \mathrm{~mm}$. As the die radius increases from 20 to $35 \mathrm{~mm}$, elongation in dimple size decreases due to reduction in stress concentration and forming load distribution. It is because there is a proper space available for stretching the sheet with the large die radius. It can also be seen in Fig. 23 that the large number 
Fig. 24 Fractographs of following sheet width (a) sheet width $25 \mathrm{~mm}$ (b) sheet width $30 \mathrm{~mm}$ (c) sheet width $35 \mathrm{~mm}$ and (d) sheet width $40 \mathrm{~mm}$, at constant die radius of $35 \mathrm{~mm}$
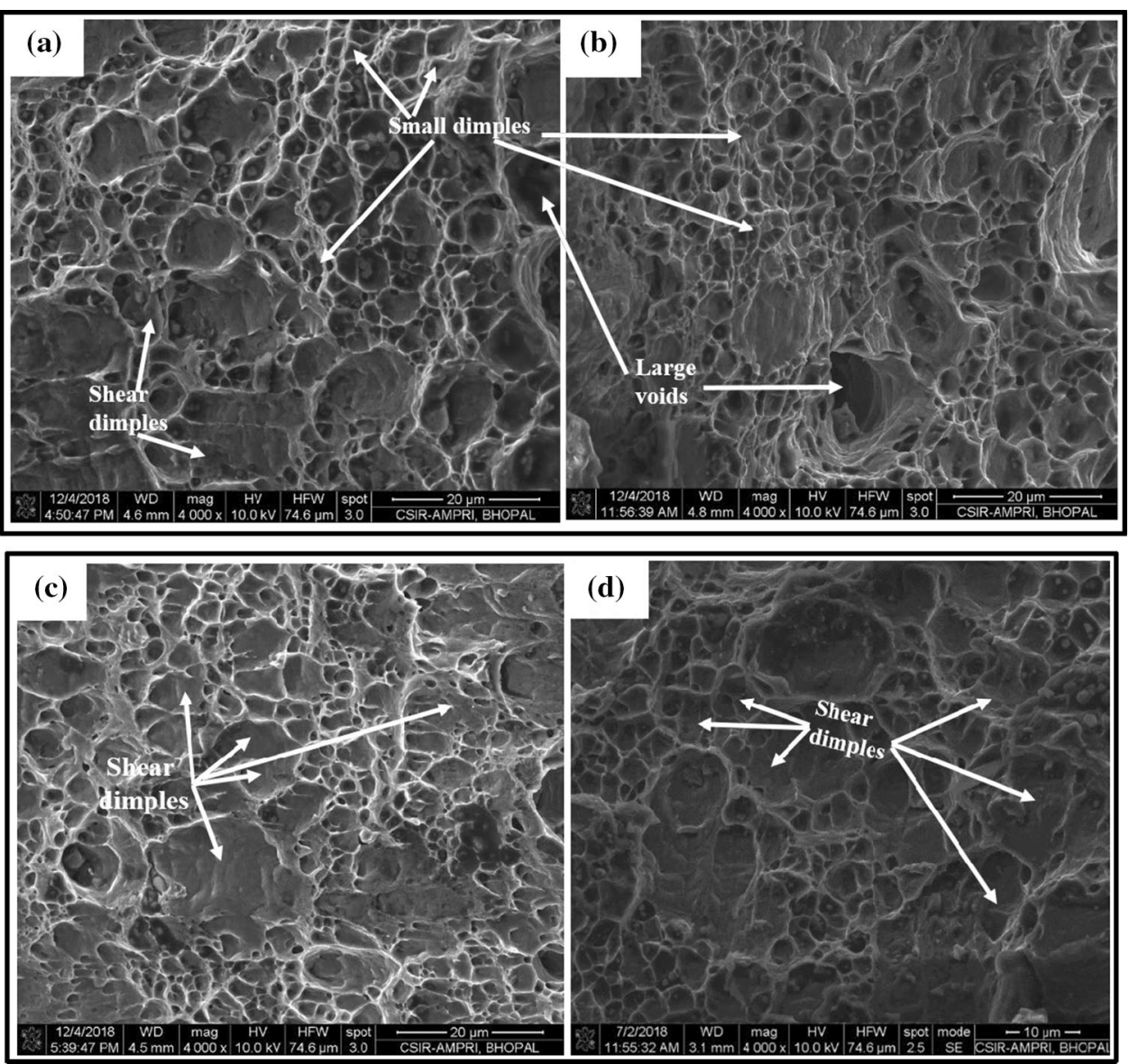

of small dimples are produced due to the fracture of the samples when large die radius is employed. It might be a reason of generation of minimum crack length at minimum forming load.

Fractographs of different samples have been also studied for different sheet width such as $25,30,35$ and $40 \mathrm{~mm}$ with a constant die radius of $35 \mathrm{~mm}$ and it is shown in Fig. 24. In the figure, small and large sized dimples are detected at minimum sheet width $(25 \mathrm{~mm})$. However, small sized dimples are comparatively more in number than large size dimples. This happens because minimum friction takes place between the tool and the sheet interface. Hence small bending force is required to bend the sheet in the case of less sheet width [1, 2]. In this condition, minimum crack length and forming load were obtained during the deformation of sheet, whereas a reverse condition was observed in the case of higher sheet width. More number of dimples was found of large size when sheet is of $40 \mathrm{~mm}$ width. It may be due to high friction between the sheet and the tool that causes the requirement of high forming load to bend the sheet $[1,2]$.

Dimple size and shape, number of dimple density and dimple distribution in fractured surface depend on the different variables such as tooling conditions, mechanical properties of the material, magnitude of forming load, strain rate etc. Finally, it can be conclude that the characteristic of the failure modes are ductile and shear types fracture because variation in dimples size, shape and its distribution are found different for different die radius and sheet width. The micrographs of fractured surface depict that there is a ductile plastic deformation and it is clear from the elongated dimples and voids.

\section{Conclusions}

In this paper, effect of sheet width and die radius in stretch flanging process of AA5052 aluminum alloy sheet were successfully studied by FE simulation and validated with experimental results. According to the observation, following outcome can be summarized:

1. Maximum crack length in the flange is obtained by FE simulation in a case when the smaller die radius is used. These results are found in very good agreement with the experimental results. Forming load is also found higher in the case when large size die radius is used. 
2. Minimum thinning in sheet is obtained in the following cases: (1) large radius of die with constant sheet width (2) smaller sheet width with constant die radius. These results are compared with the experimental one and found in very good agreement. Thinning in sheet is more affected by the die radius as compared to the sheet width. Hence, die radius should be used nearly to the width of the sheet for better formability in stretch flanging process.

3. The minimum circumferential and the radial strain are found in large die radius. Forming load is also required minimum to form the flange in higher die radius with fixed width of sheet. Crack length is also found minimum in large die radius case as compared to lower die radius. Therefore, it can be concluded that large die radius is more preferable than the smaller one for the fixed width of the sheet.

4. The circumferential and the radial strain increases with increase in the sheet width, approximately 23 and $48 \%$, respectively, when the sheet width increases from 20 to $40 \mathrm{~mm}$. Maximum forming load requirement is also increased approximately by $76 \%$ for the same case.

5. The circumferential and the radial strain decrease approximately 29.63 and $38.46 \%$, respectively, when the die radius is increased from 20 to $35 \mathrm{~mm}$ and maximum forming load also decreased by $25 \%$ for the same processing condition.

6. The crack initiates in sheet at the corner of the die and propagates toward the center of the sheet along the die profile radius in all cases.

7. Fracture phenomenon of the samples in the stretch flanging process is different for different die radius and sheet width. The large number of small dimples and more uniform distribution are found in larger die radius and smaller sheet width. Therefore, in stretch flanging process die radius should be approximately equal to the width of the sheet for better formability.

Acknowledgments The authors would like to express thanks to the Director, CSIR-AMPRI, Bhopal for the support and providing the facilities to execute this work.

Conflict of interest The authors declare that they have no conflict of interest in this work.

\section{References}

1. S. Kalpakjian, K. Vijai Sekar, S.R. Schmid, Manufacturing Engineering and Technology (Pearson, London, 2014)

2. M.P. Groover, Fundamentals of Modern Manufacturing: Materials Processes, and Systems (Wiley, New York, 2007)

3. W. Chuan-Tao, G. Kinzel, T. Altan, Failure and Wrinkling Criteria and Mathematical Modeling of Shrink and Stretch Flanging
Operations in Sheet-Metal Forming. J. Mater. Proc. Technol. 53(3), 759-780 (1995). https://doi.org/10.1016/09240136(94)01766-T

4. F. Stachowicz, Estimation of Hole-Flange Ability for Deep Drawing Steel Sheets. Arch. Civ. Mech. Eng. 8(2), 167-172 (2008). https://doi.org/10.1016/S1644-9665(12)60203-9

5. D.L. Logan, A First Course in the Finite Element Method (Cengage Learning, Boston, 2011)

6. N.-M. Wang, M. Wenner, An Analytical and Experimental Study of Stretch Flanging. Int. J. Mech. Sci. (1974). https://doi.org/10. 1016/0020-7403(74)90082-4

7. D. Li, Y. Luo, Y. Peng, P. Hu, The Numerical and Analytical Study on Stretch Flanging of V-Shaped Sheet Metal. J. Mater. Proc. Technol. 189(1), 262-267 (2007). https://doi.org/10.1016/j. jmatprotec.2007.01.035

8. W. Hu, Z. Wang, Anisotropic Characteristics of Materials and Basic Selecting Rules with Different Sheet Metal Forming Processes. J. Mater. Proc. Technol. 127(3), 374-381 (2007). https:// doi.org/10.1016/S0924-0136(02)00410-7

9. P. Hu, D. Li, Y. Li, Analytical Models of Stretch and Shrink Flanging. Int. J. Mach. Tools Manuf 43(13), 1367-1373 (2003). https://doi.org/10.1016/S0890-6955(03)00150-0

10. N. Asnafi, On Stretch and Shrink Flanging of Sheet Aluminium by Fluid Forming. J. Mater. Proc. Technol. 96(1), 198-214 (1999). https://doi.org/10.1016/S0924-0136(99)00352-0

11. H. Yoshida, T. Yoshida, K. Sato, Y. Takahashi, T. Matsuno, J. Nitta, Evaluation and Improving Methods of Stretch Flangeability. Nippon Steel Tech. Rep. 1035, 18-24 (2013)

12. S.K. Paul, Theoretical Analysis of Strain-and Stress-Based Forming Limit Diagrams. J. Strain Anal. Eng. Des. 48(3), 177188 (2013). https://doi.org/10.1177/0309324712468524

13. H. Voswinckel, M. Bambach, G. Hirt, Improving Geometrical Accuracy for Flanging by Incremental Sheet Metal Forming. Int. J. Mater. Form. 8(3), 391-399 (2015). https://doi.org/10.1007/ s12289-014-1182-y

14. Y.-H. Lu, F.-H. Yeh, C.-L. Li, M.-T. Wu, Study of Using ANFIS to the Prediction in the Bore-Expanding Process. Int. J. Adv. Manuf. Technol. 26(5-6), 544-551 (2005). https://doi.org/10. 1007/s00170-003-2024-0

15. G.E. Zhang, J. Yao, S.J. Hu, X. Wu, Shrink Flanging with Surface Contours. J. Manuf. Process. 5(2), 143-153 (2003). https:// doi.org/10.1016/S1526-6125(03)70049-8

16. L. Chen, H. Chen, Q. Wang, Z. Li, Studies on Wrinkling and Control Method in Rubber Forming Using Aluminium Sheet Shrink Flanging Process. Mater. Des. 1980-2015(65), 505-510 (2015). https://doi.org/10.1016/j.matdes.2014.09.057

17. J. Cao, M. Li, Wrinkling Analysis in Shrink Flanging. J. Manuf. Sci. Eng. (2011). https://doi.org/10.1115/1.1381397

18. M.M. Kasaei, H.M. Naeini, B. Abbaszadeh, M. Mohammadi, M. Ghodsi, M. Kiuchi, R. Zolghadr, G. Liaghat, R.A. Tafti, M.S. Tehrani, Flange Wrinkling in Flexible Roll Forming Process. Proc. Eng. 81, 245-250 (2014). https://doi.org/10.1016/j.proeng. 2014.09.158

19. X. Wang, J. Cao, An Analytical Prediction of Flange Wrinkling in Sheet Metal Forming. J. Manuf. Process. 2(2), 100-107 (2000). https://doi.org/10.1016/S1526-6125(00)70017-X

20. G. Centeno, A. Martínez-Donaire, C. Vallellano, L. MartínezPalmeth, D. Morales, C. Suntaxi, F. García-Lomas, Experimental Study on the Evaluation of Necking And Fracture Strains in Sheet Metal Forming Processes. Proc. Eng. 63, 650-658 (2013). https:// doi.org/10.1016/j.proeng.2013.08.204

21. Y. Dewang, M. Hora, S. Panthi, Prediction of Crack Location and Propagation in Stretch Flanging Process of Aluminum Alloy AA5052 Sheet Using FEM Simulation. Trans. Nonferrous Met. Soc. China 25(7), 2308-2320 (2015). https://doi.org/10.1016/S10036326(15)63846-8 
22. X. Feng, L. Zhongqin, L. Shuhui, X. Weili, Study on the Influences of Geometrical Parameters on the Formability of Stretch Curved Flanging by Numerical Simulation. J. Mater. Proc. Technol. 145(1), 93-98 (2004). https://doi.org/10.1016/S09240136(03)00866-5

23. Y. Abe, K.-I. Mori, K. Norita, Gradually Contacting Punch for Improving Stretch Flangeability of Ultra-High Strength Steel Sheets. CIRP Ann. Manuf. Technol. 62(1), 263-266 (2013). https://doi.org/10.1016/j.cirp.2013.03.059

24. P. Sartkulvanich, B. Kroenauer, R. Golle, A. Konieczny, T. Altan, Finite Element Analysis of the Effect of Blanked Edge Quality Upon Stretch Flanging of AHSS. CIRP Ann. 59(1), 279282 (2010). https://doi.org/10.1016/j.cirp.2010.03.108

25. A. Vafaeesefat, M. Khanahmadlu, Comparison of the Numerical and Experimental Results of the Sheet Metal Flange Forming Based on Shell-Elements Types. Int. J. Precis. Eng. Manuf. 12(5), 857 (2011). https://doi.org/10.1007/s12541-011-0114-8

26. S.F. Golovashchenko, Quality of Trimming and its Effect on Stretch Flanging of Automotive Panels. J. Mater. Eng. Perform. 17(3), 316-325 (2008). https://doi.org/10.1007/s11665-008-9220$\mathrm{x}$

27. T. Wen, S. Zhang, J. Zheng, Q. Huang, Q. Liu, Bi-Directional Dieless Incremental Flanging of Sheet Metals Using a Bar Tool with Tapered Shoulders. J. Mater. Proc. Technol. 229, 795-803 (2016). https://doi.org/10.1016/j.jmatprotec.2015.11.005

28. J. McDougall, M. Stevenson, K. McKeever, Analysis of Sheet Steel Fracture During Deep Drawing. J. Fail. Anal. Prev. 5(5), 20-25 (2005). https://doi.org/10.1016/j.jmapro.2017.09.033

29. R. Gupta, V.A. Kumar, M. Karthikeyan, P. Ramkumar, P.R. Narayanan, P. Sinha, Investigation of Cracks Generated in Columbium Alloy (C-103) Sheets During Deep Drawing Operation. J. Fail. Anal. Prev. 10(3), 228-232 (2010). https://doi.org/ $10.1007 / \mathrm{s} 11668-010-9341-\mathrm{z}$

30. G. Pantazopoulos, A. Sampani, Failure Analysis of Fractured Deep-Drawn 1050 Aluminum Circles. J. Fail. Anal. Prev. 6(3), 24-28 (2006). https://doi.org/10.1361/154770206X107307

31. J. Wu, F. Zou, Deep Drawing Failure Map of a Coated Metal Sheet Based on the Process Parameters. J. Fail. Anal. Prev. 16(3), 361-368 (2016). https://doi.org/10.1007/s11668-016-0097-y

32. G. Yoganjaneyulu, C.S. Narayanan, A Comparison of Fracture Limit Analysis on Titanium Grade 2 and Titanium Grade 4 Sheets
During Single Point Incremental Forming (Anal. Prev., J Fail, 2019). https://doi.org/10.1007/s11668-019-00721-y

33. S.V. Kumbhar, Pressure Optimization and Failure Prediction for Deep Drawing Process of Sheet Metal Products: A Case Study. J. Fail. Anal. Prev. 18(4), 948-956 (2018). https://doi.org/10.1007/ s11668-018-0485-6

34. S. Kumar, M. Ahmed, S.K. Panthi, Effect of Punch Profile on Deformation Behaviour of AA5052 Sheet in Stretch Flanging Process. Arch. Civ. Mech. Eng. 20, 18 (2020). https://doi.org/10. 1007/s43452-020-00016-2

35. J.R. Davis, Tensile Testing (ASM International, Ohio, 2004)

36. M. Ahmed, D.R. Kumar, M. Nabi, Enhancement of Formability of AA5052 Alloy Sheets by Electrohydraulic Forming Process. J. Mater. Eng. Perform. 26(1), 439-452 (2017). https://doi.org/10. 1007/s11665-016-2446-0

37. A. Documentation, Getting Started with Abaqus Interactive Edition, Version (2013)

38. G.E. Dieter, D.J. Bacon, Mechanical Metallurgy (McGraw-Hill, New York, 1986)

39. H. Hooputra, H. Gese, H. Dell, H. Werner, A Comprehensive Failure Model for Crashworthiness Simulation of Aluminium Extrusions. Int. J. Crashworthiness 9(5), 449-464 (2004). https:// doi.org/10.1533/ijcr.2004.0289

40. R. Kiran, K. Khandelwal, Gurson Model Parameters for Ductile Fracture Simulation in ASTM A992 Steels. Fatigue Fract. Eng. Mater. Struct. 37(2), 171-183 (2014). https://doi.org/10.1111/ffe. 12097

41. Y. Bao, Prediction of Ductile Crack Formation in Uncracked Bodies. Ph. D. thesis, Impact and Crashworthiness Lab, Massachusetts Institute of Technology, Cambridge, MA (2003)

42. F.A. McClintock, A Criterion for Ductile Fracture by the Growth of Holes. J. Appl. Mech. 35(2), 363-371 (1968). https://doi.org/ 10.1115/1.3601204

43. S. Kut, A Simple Method to Determine Ductile Fracture Strain in a Tensile Test of Plane Specimen's. Metalurgija 49(4), 295-299 (2010)

Publisher's Note Springer Nature remains neutral with regard to jurisdictional claims in published maps and institutional affiliations. 